The 20th ASTIN Colloquium, which took place in Scheveningen's KurhausHotel, was attended by around 225 active participants from 24 countries. This large number of participants and of submitted papers was a fitting cadre for this anniversary. Our Dutch colleagues had arranged a Welcome Party on Sunday evening which got things off to an extremely good start, with old and new friends striking up conversations and contacts for the first time.

The official, scientific part of the congress was opened on Monday morning by the ASTIN's president, Jean Lemaire. The Chairman of the Dutch ASTIN group, Wim DE WIT, gave a historical survey of the ASTIN papers of the past on the occasion of this 20th anniversary, and emphasized the significance of practical and empirical work. Following the opening speeches M. J. L. JONKHART, Director of Monetary Affairs of the Dutch Ministry of Finance and Professor of Finance at Erasmus University Rotterdam, held an invited lecture entitled "Towards an internal market for insurance in the EC". This interesting lecture dealt with the effects of the White Paper of the Commission to the European Council issued in 1985, which supplied considerable incentives and indicated possibilities for completing the integration of the Community markets by 1992 . JONKHART pointed out the opportunities and new liberties which could materialize if this common goal is reached, and underlined the fact that European insurance companies should start preparing for the changing conditions in 1992 early enough.

As was the case with all previous ASTIN Colloquia, the 36 submitted papers were presented and discussed on the following days. A good reception was given to the idea that each author gave a condensed version of his/her work, as well as to the opening of the general discussion by the official discussants, who had prepared remarks and questions on the papers. This procedure began with Subject 1: Rate Making. In his paper on credibility estimators in motor insurance (cf. also NEUHAUS' paper), SUNDT presents an alternative to the classical "optimal" estimators in the standard BÜHLMANN model. The geometric weights used in this method aim to supply the estimators with more robustness against deviations of the model assumptions from reality, and make the premiums more acceptable to the Norwegian policyholders. In order to make credibility theory and the resulting estimators for the pure risk premium comprehensible even to nonactuaries, managers and public officials, GISLER interprets credibility techniques from a novel point of view, focusing on the precision of credibility estimators subject to the observations available and their uncertainty. BAAIJ discusses one of the problems of disability insurance which has been arousing interest in the Netherlands for quite some time. Since the Dutch State Disability Plan only covers loss of income up to a maximum limit, a mathematical model was used to create a group insurance, covering part of any disabled employee's remaining 
loss of income subject to the structure of the insured group of staff. Referring to the reform of the Belgian motor third party tariff, LEMAIRE highlighted some basic aspects of bonus-malus systems in motor insurance, e.g. their efficiency (or fairness) and the effects of the policyholder's hunger for bonuses in such tariff systems, which are based on Markovian transition rules. He also made comparisons between the motor third party tariffs of different countries. The paper by INGENBLEEK and LEMAIRE supplies a method, of importance for third party liability premiums in Belgium, for defining the sporting nature of a vehicle. Basing their calculations on 5 variables, which depend solely on some technical characteristics of the individual car makes, the authors apply the method of principal component analysis. They succeed in determining the principal component for describing the sporting nature of a vehicle. This makes it possible to classify all vehicles according to their differing sporting natures. With regard to the UK it would be to the great advantage of motor insurers to have an information system which clearly shows the premium relativities for the whole range of risks within their portfolios. BENNETT demonstrated two methods of doing this in a very uncomplicated way. The main difference between them is that one examines the claim frequencies and average costs separately (adjusted claim cost method) and the other together (relative claim ratio method).

LEVI deals with the problem of determining variable premiums for excess of loss treaties of a long-tail nature, modelling the excess losses by means of a compound Poisson distribution with a Pareto-distributed claim size, and making particular assumptions regarding the payment pattern. KESTEMONT, KHAMAS and PARIS deal with the problem of fitting the tails of an appropriate probability distribution function to the observed large claims of a non-life insurance portfolio. They consider and compare the Pareto, Gamma, Loggamma, Lognormal and Weibull distribution, and various statistical procedures which estimate the unknown parameters on the basis of the observed data. RANTALA considers the matter of optimal reinsurance to be an arrangement between reinsurer and cedent, with a long-term character. This dynamic approach makes the use of mathematical models necessary, in which the annual reinsurance premium depends on the actual claims history. The numerical solutions to the problem are derived with the help of techniques taken from stochastic control theory and especially with the aid of the Kalman filter technique. The paper delivered by GOOVAERTS and TAYLOR concentrates on utility theory. The aim is to determine insurance premiums according to the principle of zero utility. If the utility function is exponential (i.e. constant coefficient of risk aversion), the principle has attractive properties. On the other hand, the premiums become independent of wealth, something which practitioners do not consider plausible. The authors therefore also analyse non-exponential utility functions, where the properties of zero utility premiums depend on the behaviour of the coefficient of risk aversion. HEILMANN names a transform technique for obtaining new and old premium principles from, e.g. the Lorenz curve, the total time on test transform from reliability theory or the logarithm of the moment generating function.

In keeping with tradition, the scientific part of the ASTIN Colloquium was in- 
terrupted by a day's excursion to get to know the country and its people. Thus, Tuesday's programme consisted of a sight-seeing tour to learn more about the manufacturing of typically Dutch products such as cheese and wooden clogs. Of course, the guided tour of a windmill was a must as well. After lunch in the picturesque town of Volendam on the Ijssel Sea, the coach carried on to Amsterdam for a round trip of the canals. The excursion wound up with a guided tour of a diamond cutting factory in Amsterdam.

The congress continued on Wednesday morning with Section 2, entitled "Management Information Systems". RUYGT describes the tasks, such as cost price calculations, constituting of reserves, budgeting and planning etc. assigned to his company's Management Information Department, and its structure. WESTENBERGER reports on the first phase of an assignment by the Brazilian Insurers' Association to collect statistical data, with the aim of developing a new tariff for motor insurance. The author closely examines the structure of the data and the problems of recording them. According to BOHMAN, the most important diagnostic tool in a Management Information System is an algorithm for calculating the technical reserve. So as to be able to introduce such a procedure, a means of measuring the profitability and solidity of a company is required. If both quantities are constant over a certain period of time, the technical reserve can be determined with the aid of a simple equation. NEUHAUS reports on the launching by his company of a new bonus-malus system for motor insurance. The main difference between the new system - (its theoretical basis is the abovementioned paper by SUNDT) - and the traditional one is that the discount factor is calculated on a continuous scale, and the loss of discount subsequent to a claim is not a fixed fraction but a fixed amount.

Section 3, entitled "Empirical Investigations", was opened by HøJLAND: in order to prevent premiums in Norwegian fire business, after years of good results, from being drastically and inappropriately cut due to strong competition, the author proposes using models for accurately predicting future claims. He discusses sets of models which divide the claims into groups of small, large and catastrophic claims. In his paper, RAMLAU-HANSEN investigates the catastrophe potential inherent in Danish windstorm portfolios. The statistical analysis of claims statistics is based on a model in which both the number of individual claims and their average amount depends, i.a., on the severity of the windstorm. From this starting-point, solvency margins are derived for catastrophe-prone portfolios, also taking reinsurance levels into consideration. HERTIG's paper analytically examines the effects of proportional reinsurance programmes (quota share and surplus treaties) on the fluctuations of a portfolio. The variance of the aggregate claim amount turns out to be a good measure for this. The dependence of the variance on the risk profile is specified by using a fixed claims degree distribution. GREGORIUS indicates the great extent to which the financing of medical expenses by a private health insurance company depends on correlation of cost development and changes in the age structure of the insured portfolio. By means of a concrete example, RESOORT and WILLEMSE investigate phenomena arising from the analysis of risk statistics. In particular they discuss the problem 
of deficient representativity of company statistics, the danger of confirming one's own opinion, and the impossibility of checking model assumptions.

KUON, REICH and REIMERS give an evaluation of several modern, recursive and therefore fast methods for calculating the aggregate claims distribution. Apart from analytical results, they use accuracy estimates and computation amounts for their evaluation. To this end, real portfolios with up to 100,000 policies were examined. Four Dutch papers on reserving methods bring Section 3 to a close. In two of them, PRINS explains procedures used in his direct insurance company for establishing the claims reserve. These methods have been the subject of discussion in ASTIN Netherlands. The first paper deals with the constituting of the IBNER claims reserve, the second with that of the IBNR claims reserve. PATER analyses run-off-triangles by means of autoregressive methods of order $p$. As is well known, this procedure is a generalization of the chainladder technique. Comparing first, second and higher order models, the author draws the conclusion that second order models made the best forecasts for the analysed data. Alting vON GEUSAu discusses a model for the estimation of the so-called soft-IBNR in health insurance, and analyses empirical data. The problem in this field arises from the difficulties in determining the exact amount of premiums earned in a bookyear, and from the considerable time lags of the claims payments.

Wednesday afternoon began with Speakers' Corner, with 11 papers finally being submitted. PITACCO and SIGALOTTI demonstrate that, in the case of many actuarial problems, distortions due to non-observable events lead to so-called weighted distributions. Examples for such situations can be found in the context of delays in claims settlements, the estimation of mortality rates, and effects of deductibles. Also using empirical data, RUOHONEN presents a model for the claim number process consisting of a weighted Poisson process with a threeparameter gamma distribution as a structure function. This is equivalent to a claim number process which is the sum of a Poisson process and a negative binomial process. ALTING VON GEUSAU takes a starting-point which is not unusual in health insurance, namely an age-dependent rating structure described by a polynomial formula. This concept is extended by several factors which are intended to take solidarity into account. The author points out some surprising and contradictory effects of this concept in practical applications. The paper of BRIYS and KAHANE analyses at the same time the optimal consumption, investment and insurance decisions of an individual having a specific utility function. Unlike previous insurance literature, it comes to the conclusion that the amount of insurance purchased does not monotonically depend on risk aversion. Risk theoretical models are refined by KAAS, VAN HEERWAARDEN and GOOVAERTS to further improve upper bounds for stop-loss premiums. The method used is simply to keep a restricted number of large risks as they are, instead of approximating them by a compound Poisson distribution. MASTERSON updates and extends his earlier Colloquium work on price and costs indexes so that now International Consumer Price Indexes as from 1950 are presented.

On Thursday morning, Speakers' Corner continued with the presentation of 
HIPP's paper. In the case of the classical risk process, the author derives nonparametric estimators of the ruin probability in cases where the claim size distribution or other parameters are unknown. These nonparametric estimators are consistent and asymptotically normal. Moreover, their confidence intervals are constructed by bootstrap methods. VANDEBROEK derives Pareto-optimal profit-sharing formulas in the event of both the insured and the insurer being risk-averse or risk-neutral. The dividend formulas are defined in terms of the claims experience. Considering the problem of the segmentation of an insurance portfolio into appropriate homogeneous subgroups, SCHROEDER proposes and compares some measures which describe their differing risk levels. The criterion of profitability is used to judge the efficiency of the classification thus gained. The results are evaluated with the aid of simulated data. In his paper JEWELL considers the problem of estimating the distribution of the total number of incurred but not yet reported claims arising within a fixed time interval, when only an incomplete number of such claims have been reported by some point in time. The problem of predicting the number of as yet unreported events proves to be difficult to separate from the problem of estimating the delay distribution. This question is dealt with concretely as regards various data structures. The fact that the mutual insurance of natural risks in agriculture typically involves solely catastrophe covers with long-term financing of the losses incurred leads KAHANE to construe such coverage first and foremost as a loan guarantee for farmers. The investment aspect of such insurance should therefore be taken into account by the actuaries so as to safeguard the desired interplay of assets and liabilities.

After this the two papers selected from the second ASTIN competition for young researchers were presented by the two authors, WILLMOT and DUFRESNE. The first item on the agenda of the ensuing ASTIN General Assembly was the announcement of the winner of the first prize (see below). It was made known that the next ASTIN Colloquium is to take place in New York City in two years' time between the 15th and 17th November 1989, following the meeting of the American Casualty Actuarial Society.

The 20th ASTIN Colloquium was rounded off with a very pleasurable boat trip accompanied by fine weather, and then an excellent dinner at the HulstkampHuis, in the course of which our Dutch hosts were thanked for their hospitality and the hard work they had invested in making the event so worthwhile.

SIEGFRIED KUON and AXEL REICH

\section{LIST OF PAPERS}

\section{Opening Lecture}

M. J. L. JONKHART

Towards an internal market for insurance in the EC.

\section{Subject 1: Rating Making}

B. SUNDT

Credibility estimators with geometric weights. 


\section{A. GISLER}

Another view on some credibility formulae.

J. G. BAAIJ

Permanent disability group insurance on a stop-loss basis.

\section{J. LEMAIRE}

Construction of the new Belgian motor third party tariff structure.

J.-F. INGENBLEEK and J. LEMAIRE

What is a sports car?

M. C. BENNETT

Reviewing motor insurance premium relativities.

C. LEVI

Produits financiers et détermination de la prime glissante de traités non proportionnels.

R. M. Kestemont, K. S. Khamas and J. Paris

Sur l'estimation du montant des grands sinistres.

J. RANTALA

On experience rating and optimal reinsurance.

M. J. GOOVAERTS and G. C. TAYLOR

Premium rating under non-exponential utility.

W.-R. HEILMANN

Premium calculation by transform techniques.

\section{Subject 2: Management Information Systems}

F. A. M. RUYGT

The management information department in a general insurance company.

R. WESTENBERGER

Specifying information for motor insurance tariffication.

H. BOHMAN

The heart of the matter.

W. Neuhaus

A bonus-malus system in automobile insurance.

\section{Subject 3: Empirical Investigations}

T. E. HøYLAND

Forecasting in fire insurance.

H. RAMLAU-HANSEN

Statistical analysis of policy and claims data in non-life insurance, a solvency study. Part 3: Analysis of windstorm claims.

J. HERTIG

Risk profile, claims degree, and the magnitude of fluctuations.

F. K. GREGorius

The insurance of hospitalization and sickness in the Netherlands.

A. RESOORT and A. H. Willemse

Some experiences with a risk statistic.

S. KUON, A. REICH and L. REIMERS

Panjer vs Kornya vs De Pril: A comparison from a practical point of view. 
H. J. PRINS

A practical method of reserving for reported claims.

H. J. PRINS

A practical method of reserving for IBNR claims.

R. PATER

The run-off-triangle: Least squares - against chain-ladder estimations.

B. J. J. Alting von Geusau

Soft IBNR in health insurance.

\section{Speaker's Corner}

E. PitacCO and L. Sigalotti

On weighted distributions in actuarial problems.

M. RUOHONEN

A model for the claim number process.

B. J. J. Alting von Geusau

In quest of the ASTIN-paradox: perhaps solidarity can help us?

E. BRIYS and Y. KAHANE

Risk aversion and optimal insurance revisited.

R. KaAs, A. E. VAN HeErwaARden and M. J. GoOvaERTS

On stop-loss premiums for the individual model.

N. E. MASTERSON

Inflation, an economic factor in non-life insurance.

C. HIPP

Estimators and confidence intervals for ruin probabilities.

M. VANDEBROEK

Pareto-optimal profit-sharing plans.

H. SCHROEDER

On procedures of risk segmentation.

W. S. JEWELL

Predicting IBNYR events and delays

J. KAHANE

Practical issues in insurance ratemaking: The case of natural risks in agriculture.

\section{ASTIN PRIZE FOR YOUNG RESEARCHERS}

G. Willmot (1st Prize)

Sundt and Jewell's family of discrete distributions.

F. DuFresne (2nd Prize)

Distributions stationnaires d'un système bonus-malus et probabilité de ruine.

These two prize-winning papers from the second competition for young researchers are published in this current issue of ASTIN BULLETIN, on the pages immediately following this report. 